\title{
Drug-Related Problems Among Ambulatory Heart Failure Patients on Follow-Up at Debre Berhan Comprehensive Specialized Hospital, Ethiopia
}

\author{
Abate Wondesen Tsige (D) \\ Berhan Begashaw Yikna (iD) 2 \\ Birhanetensay Masresha Altaye (iD) ${ }^{2}$ \\ 'Clinical Pharmacy Unit, Department of \\ Pharmacy, College of Health Sciences, \\ Debre Berhan University, Debre Berhan, \\ Ethiopia; ${ }^{2}$ Pharmacology and Toxicology \\ Unit, Department of Pharmacy, College \\ of Health Sciences, Debre Berhan \\ University, Debre Berhan, Ethiopia
}

Purpose: The purpose of this study was to assess drug-related problems (DRPs) among ambulatory heart failure (HF) patients attending at medical referral clinic of Debre Berhan Comprehensive Specialized Hospital, Ethiopia.

Materials and Methods: A hospital-based cross-sectional study was conducted among 344 HF patients. Drug-related problems were classified using modified Cipolle's DRP classification schemes and drug-drug interactions were assessed using Micromedex, up-to-date, and drug.com drug-drug interaction checkers. The data was entered into Epidata version 4.2.0 and analyzed using SPSS version 25.0 statistical software. Descriptive statistics were used to summarize patients' characteristics. Univariable and multivariable binary logistic regression analysis was performed to identify associated factors with dependent variables. $\mathrm{P}<0.05$ was considered statistically significant.

Results: The mean age of the study participants was $53.38 \pm 18.84$ years and nearly half (45\%) were in the age group of 31-60 years. Drug-related problems were found in $80.8 \%$ of HF patients. A total of 416 DRPs were identified. Adverse drug reaction (35.58\%) was the top DRPs identified followed by the need for additional drug therapy $(30.53 \%)$ and ineffective drug therapy (26.9\%), respectively. Diuretics (45\%), beta-blockers (BBs) $(12.42 \%)$, and angiotensin-converting enzyme inhibitors (ACEIs) (10\%) were the commonly used drug classes by study participants. The presence of comorbidity $(p<0.001)$ and level of education of study participants $(\mathrm{p}=0.03)$ had a significant association with the occurrence of DRPs. Conclusion: The prevalence of DRPs among ambulatory HF patients was high. The presence of comorbidity and the educational level of study participants had a significant association with the occurrence of DRPs. Checking potential drug-drug interactions before starting a new therapy, monitoring adverse drug reactions, ensuring sustainable availability of medications, and regular education programs are recommended to minimize DRPs.

Keywords: heart failure, drug-related problem, Cipolle's DRP classification scheme, Ethiopia

\section{Introduction}

Heart failure (HF) is a clinical syndrome characterized by typical symptoms (breathlessness, ankle swelling, and fatigue) and signs (elevated jugular venous pressure, pulmonary crackles, and peripheral edema) caused by a structural and/or functional cardiac abnormality, resulting in reduced cardiac output and/or elevated intracardiac
Correspondence: Abate Wondesen Tsige Tel +251921126837

Fax +25I II68I2065

Email Abatewondesen@dbu.edu.et 
pressure at rest or during stress. ${ }^{1}$ Heart failure causes 9.91 million losses due to disability and 346.17 billion US dollar expenditure. $^{2}$

Heart failure is an emerging worldwide threat that its prevalence and health loss burden constantly increases, especially in the young leaving in low-to middle-income countries. ${ }^{3}$ There is a lack of population-based incidence and prevalence of HF studies in sub-Saharan African countries including Ethiopia. ${ }^{4}$

Drug therapy of HF is growing more complex, thus making appropriate patient management increasingly challenging. ${ }^{5}$ Several treatment guidelines recommend the use of mineralocorticoid receptor antagonists (MRAs), beta-blockers (BBs), and angiotensin-converting-enzyme inhibitors (ACEIs), which have been shown to improve survival in patients with heart failure with reduced ejection fraction (HFrEF). ${ }^{1,6}$

Though medicines have greatly increased the quality of life, their use is also associated with a determined percentage of failures, either due to a lack of safety in any one particular patient or ineffectiveness in another. ${ }^{7}$ There has also been a consistent increase in the number of medications used in patients with $\mathrm{HF}^{8}$ and this has been associated with negative health outcomes, such as frequent hospitalization, waste of resources, and having drug-related problems. ${ }^{9}$

A drug-related problem is an undesirable event experienced by a patient that involves or is suspected to involve drug therapy that interferes with achieving the desired goals of patient therapy. ${ }^{10}$ It can arise from all stages of the medication process from prescription to follow-up treatment. ${ }^{11}$ Drug-related problems are related to clinical outcomes, health-care costs, and quality of life in cardiovascular patients. ${ }^{12}$ In patients with ambulatory HF, the prevalence of DRPs has been reported to be as high as $32.7 \%{ }^{13}$ and $96.1 \%,{ }^{14}$ respectively.

A study done in Spain in HF ambulatory clinic showed that need additional drugs therapy (45\%), ineffective drug therapy (24\%), and the drug had safety problems (33.5\%), inappropriate use of dose, drug regimen, and/or duration $(22 \%)$, adverse drug effects $(16 \%)$, and medication nonadherence of patients (14\%) were the common identified DRPs. However, $94 \%$ of them were preventable. ${ }^{15}$

There is strong evidence that morbidity related to medicines is a major health issue. A study in Spain showed that $33.3 \%$ of emergency department visits were caused by drugrelated negative outcomes (DNOs), $73 \%$ of which were preventable. ${ }^{16}$ Another study conducted in the United States indicated that emergency department visits due to medication- related adverse drug events were $28 \%$, of which $70 \%$ were preventable. ${ }^{17}$ In addition, Howard's study found $6.5 \%$ of admissions were drug-related and $67 \%$ of them were preventable. $^{18}$

Optimization of drug therapy and preventing DRPs may save some of the health-care expenditure, save lives, reduce hospital stays, and enhance patients' quality of life. ${ }^{19}$

Clinical pharmacist intervention with physicians has a positive impact on reducing DRPs among ambulatory HF patients. ${ }^{20-24}$ It would be much better to prevent DRPs than to correct them. ${ }^{25}$

To the best of our knowledge, no study has been conducted on the characteristics of DRPs among ambulatory HF patients in Debre Berhan Comprehensive Specialized Hospital (DBCSH). Moreover, studies on DRPs in ambulatory HF are limited in Ethiopia. Therefore, this study attempted to assess DRPs in outpatient HF patients.

\section{Conceptual Framework}

Based on reviewed works in the literature, different risk factors predispose HF patients to develop DRP. ${ }^{26,27}$ These factors are grouped as patient-related factors (age, socioeconomic status, level of education, dietary plan, and social habits), drug-related factors (number of prescribed medications, duration of treatment, and source of medication), and disease-related factors ${ }^{28-30}$ (Figure 1).

\section{Materials and Methods \\ Study Setting}

The study was conducted in Debre Berhan Comprehensive Specialized Hospital (DBCSH) in the North Shewa Zone of the Amhara region, Ethiopia. North Shewa Zone is one of 11 Zones in the Amhara region. It is 130 kilometers apart from Addis Ababa, the capital city of Ethiopia. It has 27 districts with different climates (Dega, Woyneadega \& Kola). Agriculture is the main livelihood of the population. ${ }^{31}$

Among the clinic in DBCSH, the adult medical referral clinic is one of them and provides cardiac care including HF treatment and follow-up. The clinic provides cardiacrelated service four days per week. On average, 50 patients were served per day and $2400 \mathrm{HF}$ patients were visiting the clinic within the study period.

\section{Study Design and Population}

A hospital-based cross-sectional study design was used. The study was undertaken in two phases. The first was a patient interview phase, while the second was a 


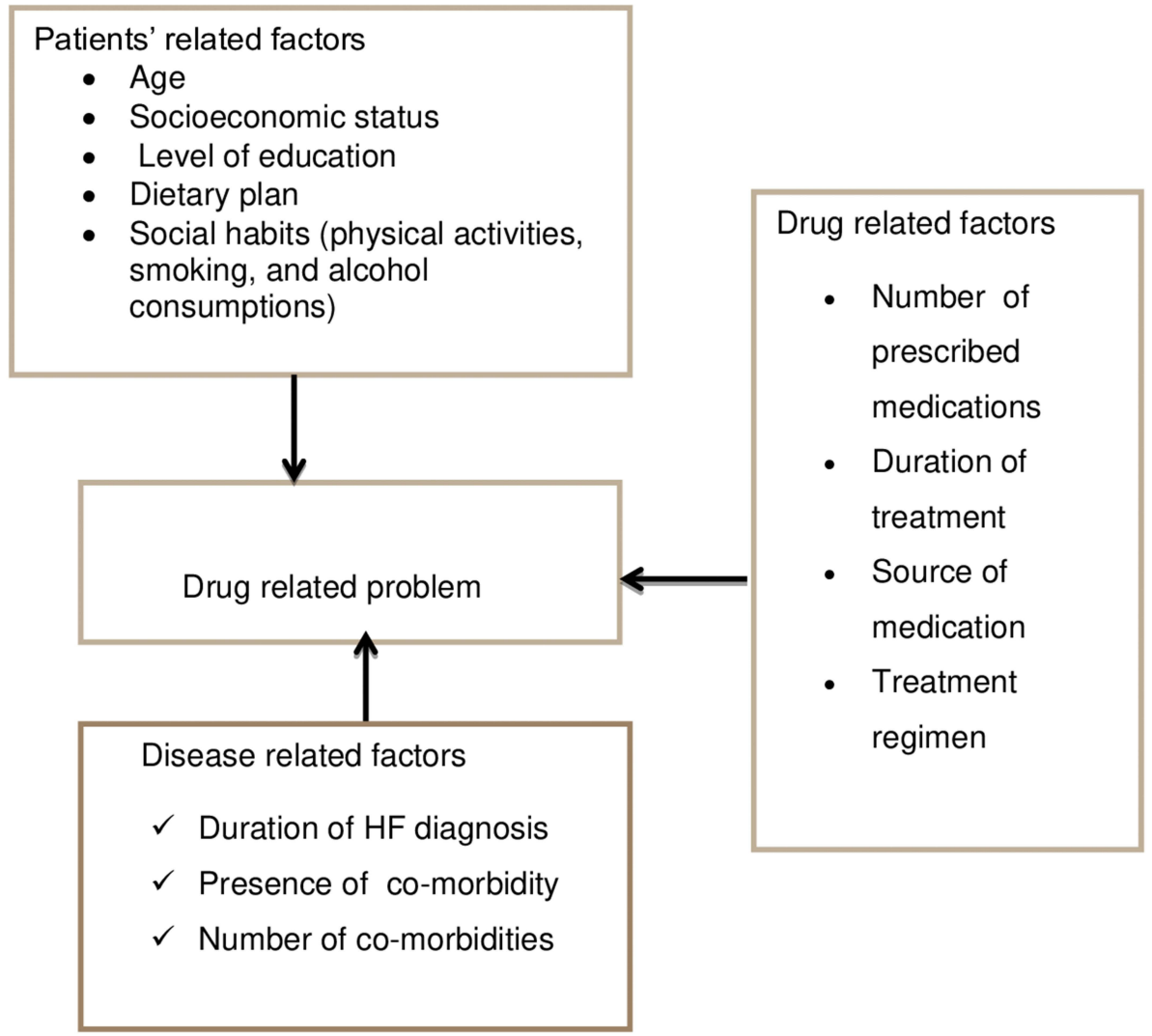

Figure I Conceptual framework showing factors involved in drug-related problems.

retrospective patient chart review. The two phases were carried out for the same patient from 1st February 2021 to 1st May 2021.

All ambulatory HF patients with the age of $\geq 18$ years who had regular follow-up and complete medical records as well as those willing to participate in the study were included in the study.

\section{Sample Size Determination and Sampling Technique}

The sample size was computed using a single population proportion formula. Considering $65 \%$ prevalence of DRP in Ethiopia ${ }^{32}, 5 \%$ margin of error at 95\% confidence level, and $10 \%$ of the contingency of non-response rate, the calculated final corrected sample size was 344 .

Study participants were selected by obtaining their medical record list from Health Management Information Systems (HMIS) of the DBCSH medical referral clinic. During the three-month study period, HF patients who had an appointment at the medical referral clinic of DBCSH were made the sampling frame, and then the sampling fraction was calculated. The average number of patients who come to the clinic was 50 attendees per day. The total sample size (344) was divided by the number of days the clinic provides service within three months (48 days) of the study period to get the study participants per day. For better representativeness of the sample, 8 patients were sampled each day based on the calculation. A systematic random sampling technique was employed based on the HMIS list of patient appointment records by calculating sampling interval as $\mathrm{K}=\mathrm{N} / \mathrm{n}$ (where $\mathrm{N}$ (50) average number of patients per day; $\mathrm{n}(8)$ is a sample to be taken per day). The study participant's medical card numbers were taken every seven intervals for chart review and then selected study participants had interviews after physicians' visits.

\section{Study Variables}

Drug-related problem was dependent variable whereas patient demographic features, social habits, clinical characteristics, and medication-related factors were independent variables.

\section{Data Collection Procedure and Analysis}

Data were collected using pre-tested questionnaires and by reviewing medical follow-up records of $\mathrm{HF}$ patients using 
data abstraction tools. A pre-test study (5\%) was conducted on HF patients and study participants who had been involved in the pre-test were excluded from the study. The questionnaire was assessed for its clarity, the time it takes, completeness, and the necessary correction was done accordingly before implementing it in the main study.

The adequacy of HF therapy was assessed using the European Society of Cardiology ${ }^{1}$ and American Heart Association/American College of Cardiology (AHA/ ACC) HF guidelines. ${ }^{6}$

Drug-related problems were identified and classified according to a modified Cipolle's DRP classification schemes. ${ }^{10}$ Three clinical pharmacists and two nurses had taken training to carry out the data collection. The clinical pharmacists were involved in chart review to identify DRPs whereas; the nurses were involved in patient interviews.

All data were sorted, cleaned, coded, and summarized on the master sheet. Data checks and corrections were done to make them ready for analysis. Data were fed into Epidata version 4.2.0 and exported to statistical package for social sciences (SPSS) version 25 software.

Binary logistic regression analysis was performed to look into the association between the occurrence of DRPs and independent variables. All variables with a $p$-value $<0.25$ in the univariable binary logistic regression analysis were included in the multivariable binary logistic regression analysis, which was performed to determine the potential predictors of DRPs. A P $<0.05$ was considered statistically significant.

\section{Ethical Consideration}

Ethical clearance of the study (P008/02/2021) was obtained from Debre Berhan University Institutional Review Board (IRB). Before data collection, study participants were informed about the study, and written informed consent was obtained before the beginning of the study. Each study participant was informed about the objective of the study, assurance of confidentiality, procedures of selection, and their rights to refuse to participate in the study. To minimize social desirability bias and enhance anonymity, no identifiers were used.

This study was conducted in accordance with the Declaration of Helsinki.

\section{Results}

\section{Socio-Demographic Characteristics of Study Participants}

In the present study, the mean age of participants was $53.38 \pm 18.84$ years and $(45 \%)$ of them were in the age group of 31-60 years. The majority of study participants (45.1\%) were married and $54.4 \%$ of patients were living out of Debre Berhan town. About two-thirds (65.1\%) were female, more than one-third (34.9\%) of study participants had no formal education, and $51.2 \%$ of them got their medication for free (Table 1).

\section{Clinical Characteristics of the Study Participants}

As shown in Table 2, nearly three-fourths (72.7\%) of study participants had less than and equal to four years followup. More than half $(54.9 \%)$ patients were in NYHA functional class IV and only five patients (1.4\%) were experienced drug allergy history.

\section{Common Etiology of Heart Failure Among Study Participants}

In our study, degenerative valvular heart disease, cor-pulmonale, congenital heart disease accounted for $31 \%$ of $\mathrm{HF}$ etiology. Chronic rheumatic valvular heart disease (CRVHD) (29\%), ischemic heart disease (IHD) (16\%), and hypertensive heart disease (HHD) (16\%), respectively, were common etiologies of HF (Figure 2).

\section{Type and Number of Co-Morbidities}

\section{Among Heart Failure Patients}

Nearly two-third, $221(64.2 \%)$ patients had co-morbid conditions. Single comorbidity was found in 156 (45.4\%) patients while $19.5 \%$ of the patients had two or more comorbidities. A maximum of three co-morbidities were seen.

The most commonly encountered cardiac-related comorbidities were hypertension (HTN) (20.1\%), atrial fibrillation (AF) (16.2\%), and thyrocardiac disease (9.6\%), respectively. Lung disease accounted for $12 \%$ of non-cardiac comorbidities (Figure 3).

\section{The Pattern of Cardiovascular Drug Uses Among the Study Participants}

A total of 1095 drugs were used for HF and co-morbidities management. Diuretics (45\%), BB (12.4\%) followed by ACEIs (10\%) were the commonly used drugs. From the diuretics, the most frequently prescribed specific drugs were furosemide $(55 \%)$ followed by spironolactone $(42.32 \%)$ (Table 3). 
Table I Socio-Demographic Characteristics of Study Participants Attending Medical Referral Clinic of DBCSH from February to June 2021

\begin{tabular}{|c|c|c|c|c|}
\hline Variables & Categories & Number (\%) & Mean \pm SD & Range \\
\hline \multicolumn{5}{|l|}{ Sex } \\
\hline & Male & $120(34.9)$ & & \\
\hline & Female & $224(65.1)$ & & \\
\hline \multicolumn{5}{|l|}{ Age (years) } \\
\hline & Young adult (18-30) & $56(16.3)$ & & \\
\hline & Adult $(31-60)$ & $155(45)$ & $53.38 \pm 18.84$ & $18-92$ years \\
\hline & Elderly $(>60)$ & $133(38.7)$ & & \\
\hline \multicolumn{5}{|l|}{ Religion } \\
\hline & Orthodox & $255(74.1)$ & & \\
\hline & Muslim & $42(12.2)$ & & \\
\hline & Catholic & $15(4.4)$ & & \\
\hline & Protestant & $32(9.3)$ & & \\
\hline \multicolumn{5}{|l|}{ Marital status } \\
\hline & Single & 78 (22.7) & & \\
\hline & Married & I55 (45.I) & & \\
\hline & Widowed & $64(18.6)$ & & \\
\hline & Divorced & $47(13.6)$ & & \\
\hline \multicolumn{5}{|l|}{ Educational status } \\
\hline & Unable to write and read & $120(34.9)$ & & \\
\hline & Primary & 7I (20.6) & & \\
\hline & Secondary & $74(2 \mid .5)$ & & \\
\hline & Diploma and above & $79(23.0)$ & & \\
\hline Place of residence & Debre Berhan & I57 (45.6) & & \\
\hline & Out of Debre Berhan & $187(54.4)$ & & \\
\hline \multirow[t]{8}{*}{ Occupation } & Governmental Employed & $57(16.5)$ & & \\
\hline & Private employed & $45(13.1)$ & & \\
\hline & Unemployed & $99(28.8)$ & & \\
\hline & Farmer & $39(11.3)$ & & \\
\hline & Housewife & $25(7.3)$ & & \\
\hline & Merchant & $44(12.8)$ & & \\
\hline & Retired & $14(4.1)$ & & \\
\hline & Others* & $21(6.1)$ & & \\
\hline \multicolumn{5}{|c|}{ Monthly income (Birr) ** } \\
\hline & Low $(<1500)$ & $257(74.7)$ & & \\
\hline & Average $(I 50 \mathrm{I}-3000)$ & $44(12.8)$ & & \\
\hline & Above average $(300 \mathrm{I}-5000)$ & $30(8.7)$ & & \\
\hline & High ( $\geq 500 \mathrm{I})$ & $13(3.8)$ & & \\
\hline \multicolumn{5}{|c|}{ Source of medications } \\
\hline & Free & $176(5 \mid .2)$ & & \\
\hline & Paid & $147(42.7)$ & & \\
\hline & Covered by insurance & $21(6.1)$ & & \\
\hline
\end{tabular}

Notes: *Guard, Mechanics, Student. **Based on the Ethiopian Civil Service monthly Salary scale of Civil Servants. 
Table 2 Clinical Characteristics of Heart Failure Patients Attending at Medical Referral Clinic of DBCSH from February to June 202I

\begin{tabular}{|l|l|l|}
\hline Clinical Characteristics & Category & Number (\%) \\
\hline Follow-up & $\leq 4$ years & $250(72.7)$ \\
& $5-8$ years & $60(17.4)$ \\
& $>8$ years & $34(9.9)$ \\
\hline Frequency of follow UP & $\leq 3$ month & 34 I (99.1) \\
& $\geq 3$ month & $3(0.9)$ \\
\hline NYHA & Class II & $1(0.3)$ \\
& Class III & $1(0.3)$ \\
& Class IV & $190(55.2)$ \\
\hline Stage of HF & C & $192(55.8 I)$ \\
& No documented Stage of HF & $152(44.19)$ \\
\hline Known drug allergy & No & $339(98.6)$ \\
& Yes & $5(1.4)$ \\
\hline
\end{tabular}

\section{Drug-Related Problems}

A total of $275(80 \%)$ participants had one or more DRP/s. A total of 416 DRPs were identified. One DRP was identified in $176(51.2 \%)$ patients, whereas 2 and $\geq 3$ DRPs were identified in $74(21.5 \%)$ and $25(7.3 \%)$ patients, respectively. The mean number of DRPs per patient was $1.2 \pm 0.84$.

The most frequently identified DRPs were drug interaction (33.4\%), need additional therapy (30.53\%), and ineffective drug therapy (26.9\%) (Table 4).

The most frequent drug classes involved in DRPs were diuretics (41.18\%), BB (25.49\%) followed by ACEIs $(15.69 \%)$.

\section{Predictors of Occurrence of Drug- Related Problems}

Vulnerability to DRPs needs to be identified to identify vulnerable study participants. The perceived demographic

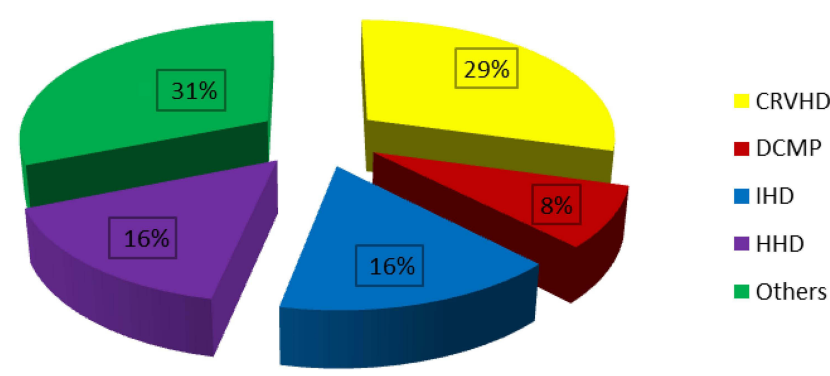

Figure 2 Etiology of heart failure participants attending at medical referral clinic of DBCSH from February to June 202I. Others; Degenerative Valvular Heart Disease, Cor-pulmonale, Congenital Heart Disease.

Abbreviations: IHD, ischemic heart disease; HHD, hypertensive heart disease; CRVHD, chronic rheumatic valvular heart disease; CMP, cardiomyopathy. and clinical characteristics which fulfilled the multi-variable logistic regression analysis were the presence of comorbidity, study participants' educational level, presence of dietary plan with physicians, age group, and the number of comorbidities.

Our finding showed that the educational level of patients and the presence of comorbidity were significantly associated with the occurrence of DRPs. Patients with comorbidity were 10 times more likely to develop at least one DRP compared to patients with no comorbidities (adjusted odds ratio $[\mathrm{AOR}]=10,95 \% \mathrm{CI}=4.24-26, \mathrm{p}$ $<0.001$ ). The odds of DRP were 0.38 times less likely

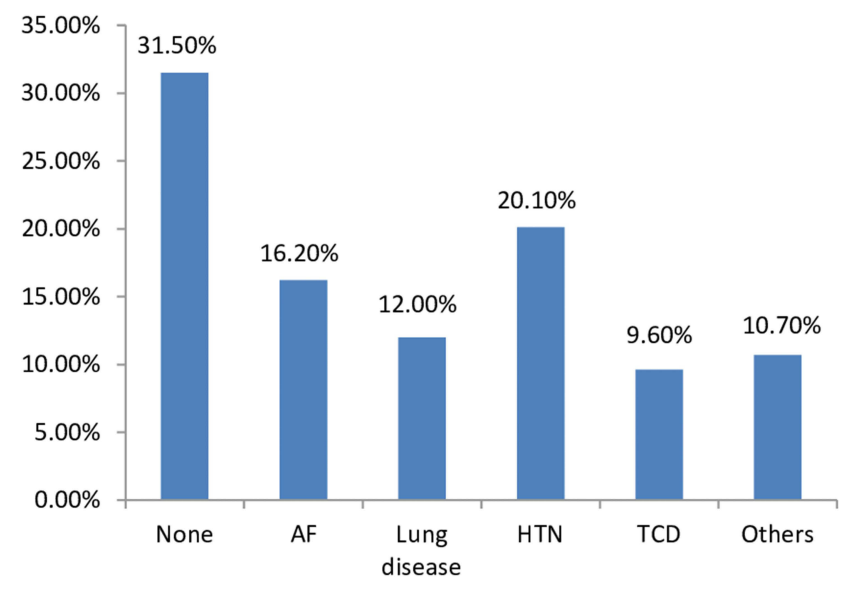

Figure 3 Co-morbid conditions of heart failure participants attending at medical referral clinic of DBCSH from February to June 2021. Others: Chronic kidney disease (CKD), Benign prostate hyperplasia (BPH), peripheral arterial disease (PAD), anemia, chronic liver disease (CLD), left atrial thrombus, polycythemia, major depressive disorder (MDD), pulmonary thrombus embolism, TB pericarditis, systemic lupus erythematosus, diabetic mellitus, epilepsy.

Abbreviations: AF, atrial fibrillation; HTN, hypertension; $T C D$, thyrocardiac disease. 
Table 3 Pattern of Medication Use Among Heart Failure Patients Attending at Medical Referral Clinic of DBCSH, from February to June 2021

\begin{tabular}{|c|c|c|}
\hline Variables & Frequency & Percent \\
\hline Diuretics & 495 & 45.2 \\
\hline Furosemide & 272 & \\
\hline Spironolactone & 210 & \\
\hline Hydrochlorothiazide & 13 & \\
\hline Beta-blockers & 136 & 12.4 \\
\hline Atenolol & 38 & \\
\hline Metoprolol & 68 & \\
\hline Propranolol & 30 & \\
\hline Anticoagulants & 24 & 2.3 \\
\hline Warfarin & 23 & \\
\hline Rivaroxaban & 1 & \\
\hline $\begin{array}{l}\text { Angiotensin-Converting Enzyme Inhibitor } \\
\text { Enalapril }\end{array}$ & 110 & 10 \\
\hline Cardiac Glycoside & & 3.2 \\
\hline Digoxin & 35 & \\
\hline Anti-Diabetic Medications & & 0.3 \\
\hline NPH Insulin & 3 & \\
\hline Calcium Channel Blockers & 24 & 2.3 \\
\hline Amlodipine & 23 & \\
\hline Nifedipine & 1 & \\
\hline Anti-platelets & 98 & 8.9 \\
\hline Aspirin & 95 & \\
\hline Clopidogrel & 3 & \\
\hline Other medications & 106 & 9.6 \\
\hline Statins & 64 & \\
\hline Benzathine penicillin & 42 & \\
\hline Others* & 64 & 5.8 \\
\hline Total number of medications & 1095 & 100 \\
\hline
\end{tabular}

Note: *Anticoagulant, Statin, a tricyclic antidepressant, Carbimazole.

among patients who had secondary education as compared to patients with no formal education ( $\mathrm{AOR}=0.38,95 \% \mathrm{CI}$ $=0.16-0.92, \mathrm{p}=0.03)($ Table 5).

\section{Discussion}

Heart failure patients are at high risk of having DRPs owing to the presence of comorbidity, poly-pharmacy, and complexity of drug regimens. ${ }^{13,33}$ Identification of DRP and factors associated with them is critical for the prevention of DRPs and improving health outcomes. ${ }^{34}$ The present study was aimed to determine DRPs among HF patients at the adult medical referral clinic of DBCSH.
This study revealed that the mean age of study participants was $53.38 \pm 18.84$, and the predominant portion of the study subjects were (45\%) 31-60 age groups. Based on our findings, being older had more prone to DRPs. This is comparable with similar study findings conducted elsewhere. ${ }^{13,14,35}$

About two-thirds of participants were females (65.1\%), which was consistent with other studies ${ }^{33,35}$ but not with studies conducted in Taiwan ${ }^{13}$ and India. ${ }^{36}$ The discrepancy could be due to differences in the study setting. The current study was conducted in outpatient medical referral clinics while some of the above studies were conducted in the inpatient clinics.

Most participants were NYHA class IV stage C HF (55.81\%). This finding was inconsistent with a study conducted by Hsu et al. ${ }^{13}$

Nearly one-third of the study participants $(35.2 \%)$ did not have coexisting co-morbidities. However, $45.3 \%$ and $19.5 \%$ of patients were diagnosed with one, two, and above co-morbidities, respectively. This finding was different from a study conducted in India by Shareef et al indicated that the majority of participants had concurrent co-morbidities. ${ }^{36}$ The possible reason could be, Shareef et al, a study carried out among inpatient CVD patients while the current study was conducted at outpatient HF patients. In our study, HTN (20.1\%) and AF (16.2\%) were the most common co-morbidities while DM and HTN were in Taiwan. ${ }^{13}$

In the present study, 1095 drugs were used by the study participants, which was lower than a similar study done by Seid et al (2097 drugs), ${ }^{37}$ but higher than Tegegne et al, study (230 drugs). ${ }^{14}$ Diuretics were the most widely used treatment regimen in outpatient $\mathrm{HF}$ patients at DBCSH accounting for $(45 \%)$, which is higher than a similar study done in Taiwan $(21 \%){ }^{13}$ This could be due to our study conducted in a resource-limited setting where there is a shortage of drugs with morbidity and mortality benefit of HF.

A total of 416 DRPs were identified with a mean number of $1.2 \pm 0.84$ per patient. This finding was fairly higher than the study conducted in Australia (147 DRPs with $1.5 \pm 1.4$ per patient) ${ }^{15}$ Bonga, Ethiopia (163 DRPs with $1.08 \pm 0.75$ per patient), ${ }^{33}$ Jimma, Ethiopia (105 DRPs with $1.38 \pm 0.8),{ }^{14}$ India $(53 \mathrm{DRPs}){ }^{36}$ but lower than a study in Spain (448 DRPs with the mean number of $1.8 \pm 1.08$ per patient) ${ }^{34}$ Taiwan (796 DRPs). ${ }^{13}$ The differences could be attributed to there is no involvement of clinical pharmacist in the multidisciplinary team of HF 
Table 4 Types of Drug-Related Problems Identified from Heart Failure Patients Attending at Medical Referral Clinic of DBCSH from February to June 2021

\begin{tabular}{|l|l|l|l|l|}
\hline DTPs & & No. DTPs & Total & (\%) \\
\hline Adverse drug reaction & $\begin{array}{l}\text { Drug interaction } \\
\text { Undesirable effect }\end{array}$ & $\begin{array}{l}139 \\
9\end{array}$ & 148 & 35.6 \\
\hline Need additional therapy & $\begin{array}{l}\text { Untreated medical condition } \\
\text { Need prophylactic/preventive drug }\end{array}$ & $\begin{array}{l}23 \\
104\end{array}$ & 127 & 30.5 \\
\hline Ineffective drug & $\begin{array}{l}\text { More effective drug available } \\
\text { Drug not indicated for the condition }\end{array}$ & 7 & 105 & 26.9 \\
\hline Inappropriate dose & $\begin{array}{l}\text { Dose too low } \\
\text { Dose too high }\end{array}$ & 7 & 12 & 2.9 \\
\hline Unnecessary drug therapy & $\begin{array}{l}\text { No medical indication } \\
\text { Duplicate therapy }\end{array}$ & 13 & 17 & 4.1 \\
\hline Total & & 4 & 416 & 100 \\
\hline
\end{tabular}

Table 5 Predictors of Occurrence of Drug-Related Problems in Heart Failure Patients Attending at Medical Referral Clinic of DBCSH, from February to June 2021

\begin{tabular}{|c|c|c|c|c|c|c|}
\hline \multirow[t]{2}{*}{ Variables } & \multirow[t]{2}{*}{ Category } & \multicolumn{2}{|l|}{ DRP (\%) } & \multirow[t]{2}{*}{ COR $(95 \% \mathrm{Cl})$} & \multirow[t]{2}{*}{ AOR (95\% CI) } & \multirow[t]{2}{*}{ P. Value } \\
\hline & & Yes & No & & & \\
\hline \multirow[t]{2}{*}{ Co-morbidity } & No & $106(71.6)$ & $42(28.4)$ & 1 & I & \\
\hline & Yes & $188(95.9)$ & $8(4.1)$ & 9.31 (4.23-20.57) & $10(4.24-26)$ & $<0.001 *$ \\
\hline \multirow[t]{2}{*}{ Dietary plan with physicians } & No & $21(18.8)$ & $98(81.3)$ & I & I & \\
\hline & Yes & $29(12.5)$ & $203(87.5)$ & $1.62(0.87-2.98)$ & I.68 (0.82-3.45) & 0.16 \\
\hline \multirow[t]{4}{*}{ Educational level } & No formal education & $106(88.3)$ & 14 (II.7) & 1 & I & \\
\hline & Primary & 56 (78.9) & I5 (2I.I) & $0.49(0.22-1)$ & $0.45(0.18-1)$ & 0.08 \\
\hline & Secondary & $57(77)$ & $17(23)$ & $0.44(0.20-0.96)$ & $0.38(0.16-0.92)$ & $0.03 *$ \\
\hline & Diploma and above & 75 (94.9) & $4(5.1)$ & $2.48(0.78-7.82)$ & $2.45(0.7 \mathrm{I}-8.44)$ & 0.16 \\
\hline \multirow[t]{3}{*}{ Age } & $18-38$ & $64(78$ & $18(22)$ & I & 1 & \\
\hline & $39-59$ & $109(87.9)$ & $15(12.1)$ & $2.04(0.96-4.33)$ & $1.08(0.44-2.64)$ & 0.87 \\
\hline & $\geq 60$ & $12 \mid(87.7)$ & $17(12.3)$ & $2(0.97-4.15)$ & $1.52(0.64-3.58)$ & 0.34 \\
\hline \multirow[t]{3}{*}{ Number of Comorbidities } & None & 95 (79.2) & $25(20.8)$ & 1 & 1 & \\
\hline & 1 & $133(85.3)$ & $23(14.7)$ & $1.52(0.82-2.84)$ & $0.46(0.20-1)$ & 0.05 \\
\hline & $\geq 2$ & $65(97)$ & $2(3.08)$ & $8.55(1.96-37.3)$ & $2.40(0.48-11.98)$ & 0.26 \\
\hline
\end{tabular}

Note: *: Statistically significant at $\mathrm{p}<0.05$.

care in the current study and Taiwan during the study period whereas, in Australia, there is clinical pharmacist involvement in patient care; differences in the classification and operationalization of DRPs (for example, the study done in Taiwan, the DRPs were defined according to the definition of the Pharmaceutical Care Network Europe (PCNE)); nature of patients included in the study (for example, the study conducted in Spain included CVD patients at cardiology ward), and the higher number of
DRPs in our study maybe there is no national standard treatment protocol for HF patients.

From adverse drug reactions, drug-drug interactions $(148,35.58 \%)$ were the most prevalent DRPs. This finding was in agreement with a study done in Spain $^{34}$ and India, ${ }^{36}$ but higher than a study done in Switzerland ${ }^{12}$ and lower than a finding reported by the USA study. ${ }^{38}$ The higher prevalence of DDI may be due to multiple drug regimens used for HF treatment. 
Among indication-related problems, the need for prophylactic/preventive drug therapy $(127,30.53 \%)$ was the second common DRPs. A similar finding was obtained in a Barcelonan study (28.6\%), ${ }^{15}$ but our finding was lower than a study done in Boston (43\%). ${ }^{38}$ A lower prevalence was reported from similar studies done in India $(9.43 \%)^{36}$ and Taiwan $(7 \%) .{ }^{13}$

In this study, evidence-based BB (metoprolol succinate and carvedilol) and ACEIs were the most common needs for prophylactic/preventive drug therapy. It was also a common problem in a study done in India. ${ }^{36}$

The third most common DRP was ineffective drug therapy (26.9\%). This finding was in contrast with the study conducted by Shareef et al, ${ }^{36}$ in which effectiveness related to DRP was found to be low $(13.2 \%)$. In another study done by Dempsey et al, effectiveness-related DRPs were accounted for higher $(80 \%){ }^{38}$ This difference could be the Dempsey et al, study was followed patients for 4 months, providing sufficient time for detection of DRPs.

Unnecessary drug therapy was the fourth DRPs. It was found in $(17,4.1 \%)$ patients, of which no medical indication was the common one $(13,3.1 \%)$. This was in agreement with studies done in India $(5.66 \%){ }^{36}$ Australia $(4.8 \%),{ }^{15}$ Spain $(3.13 \%),{ }^{34}$ but was higher than Alazzam et al, studies $(2.47 \%){ }^{39}$

Relatively, a small number of inappropriate doses (dose too low and dose too high) $(12,2.9 \%)$ were obtained of the total DRPs. Dose too low was identified in $1.7 \%$ of patients, which was in contrast with studies done in India $(10.4 \%),{ }^{40}$ Spain $(6.7 \%),{ }^{34}$ and Addis Ababa, Ethiopia $(9 \%) .{ }^{37}$ In the present study, ACEIs and evidence-based BB were not titrated up towards established ESC and AHA guidelines recommended target doses. These lead to inadequate inhibition of the renin-angiotensin-aldosterone system by ACEI on ventricular remodeling, norepinephrine release, vasoconstriction, sodium and water retention, and preventing myocardial fibrosis, myocyte apoptosis, and cardiac hypertrophy. ${ }^{41}$ To achieve adequate inhibition of the renin-angiotensin-aldosterone system, the above drugs should be up-titrated to the maximum tolerated dose that has been reported to be effective in clinical trials in stable patients. ${ }^{1}$

In our study, dose too high was recognized as DRPs in 5 study participants. This finding was lower than a study conducted by Gizawu et al, in Bonga, Ethiopia $(11,6.75 \%),{ }^{33}$ Dempsey et al study in the USA $(9,13 \%),{ }^{38}$ and Hsu et al study in Taiwan $(12,1.5 \%) .{ }^{13}$ This variation could be attributed to differences in study methods. For example, Hsu et al study was a pharmacist-driven interventional study.

Diuretics, BB, anticoagulants, and antiplatelet were the most common drug classes involved in DRPs. This finding was concordant with Gastelurrutia et al study, ${ }^{15}$ but not with Seid et al findings. ${ }^{37}$ This difference might be; Seid et al, a study was conducted at a tertiary hospital in which patients may have a serious cardiac problem, much comorbidity, and they may take multiple CVD medications.

The results of this study showed that the presence of comorbidity and educational levels of patients were found to be independent predictors and a statistically significant association was noticed. Patients with comorbidity were 10 times more likely to develop DRPs compared to patients who had no comorbidity $(\mathrm{AOR}=10,95 \% \mathrm{CI}=$ 4.24-26, $\mathrm{p}<0.001)$. This finding was comparable with studies reported in India ${ }^{40}$ and Jordan ${ }^{39}$ indicated that the presence of certain medical conditions was associated with the presence of DRPs, but in contrast with a study reported by Gelchu and Abdela, the presence of co-morbid illness was not significantly associated in the occurrence of DTPs among patients with CVD. ${ }^{42}$

The odds of DRPs were 0.38 times less likely among patients who had secondary education as compared to patients who had no formal education (AOR $=0.38,95 \%$ $\mathrm{CI}=0.16-0.92, \mathrm{p}=0.03$ ), which was in line with Alazzams's finding. ${ }^{39}$ Nevertheless, this result was dissimilar from studies reported in Australia, ${ }^{15}$ Boston, ${ }^{38}$ and Taiwan. ${ }^{13}$

Several studies conducted elsewhere reported that poly-pharmacy was positively associated with DRPs. ${ }^{11,15,34,36}$ Conversely, this study indicated that a number of medications were not a statistically significant predictor of DRPs.

This study has tried to assess the current situation of DRPs among heart failure patients using standardized DRPs identification criteria, the use of retrospective and prospective patient data, and a panel of experts involved in DRP identification. We believe that hospitals implement clinical pharmacy services for timely detection, prevention, and resolution of DRPs. Further studies with a follow-up of patients and with intervention may be considered.

\section{Conclusion}

The findings of this study showed that drug-related problems were common among ambulatory heart failure patients. Adverse drug reaction was the top-ranking DRP followed by the need for additional drug therapy and ineffective drug therapy. 
Diuretics, BB, and ACEIs were the most frequent drug classes involved in DRPs. The presence of comorbidity and the educational level of study participants had a significant association with the occurrence of DRPs. Conjointly; this finding will be useful in the management of heart failure and could serve as a framework for further research on a related topic.

\section{Acknowledgments}

We are very thankful to the medical referral clinic staff of DBCSH for their cooperation in the data collection process and the study participants for their willingness to participate in this study.

\section{Disclosure}

The authors report no conflicts of interest in this work.

\section{References}

1. Ponikowski P, Voors AA, Anker SD, et al. 2016 ESC guidelines for the diagnosis and treatment of acute and chronic heart failure: the task force for the diagnosis and treatment of acute and chronic heart failure of the European Society of Cardiology (ESC) developed with the special contribution of the Heart Failure Association (HFA) of the ESC. Eur Heart J. 2016;37:2129-2200.

2. Lippi G, Sanchis-Gomar F. Global epidemiology and future trends of heart failure. AME Med J. 2020;5:15. doi:10.21037/amj.2020.03.03

3. Glezeva N, Gallagher J, Ledwidge $M$, et al. Heart failure in subSaharan Africa: a review of the etiology of heart failure and the role of point-of-care biomarker diagnostics. Trop Med Int Health. 2015;20 (5):581-588. doi:10.1111/tmi.12461

4. Ali S, Misganaw A, Worku A, et al. The burden of cardiovascular diseases in Ethiopia from 1990 to 2017: evidence from the global burden of disease study. Int Health. 2020;13(4):318-326.

5. Chiatti C, Bustacchini S, Furneri G, et al. The economic burden of inappropriate drug prescribing, lack of adherence and compliance, adverse drug events in older people: a systematic review. Drug Saf. 2012;35(Suppl 1):73-87. doi:10.1007/BF03319105

6. Yancy CW, Jessup M, Bozkurt B, et al. 2017 ACC/AHA/HFSA focused update of the 2013 ACCF/AHA guideline for the management of heart failure: a report of the American College of Cardiology/American Heart Association task force on clinical practice guidelines and the Heart Failure Society of America. Circulation. 2017;136:e137-e161.

7. Fernández-Llimós F, Tuneu L, Baena MI, Garcia-Delgado A, Faus MJ. Morbidity and mortality associated with pharmacotherapy. Evolution and Current Concept of Drug-Related Problems. Curr Pharm Des. 2004;10:3947-3967.

8. Brager R, Sloand E. The spectrum of polypharmacy. Nurse Pract. 2005;30(6):44-50. doi:10.1097/00006205-200506000-00008

9. Page RL, O’Bryant CL, Cheng D, et al. Drugs that may cause or exacerbate heart failure: a scientific statement from the American Heart Association. Circulation. 2016;134(6):e32-e69. doi:10.1161/ CIR.0000000000000426

10. Cipolle RJ, Strand LM, Morley PC. Chapter 5. Drug Therapy Problems. In: Cipolle RJ, Strand LM, Morley PC, editors. Pharmaceutical Care Practice: The Patient-Centered Approach to Medication Management Services. 3rd ed. New York, NY: The McGraw-Hill Companies; 2012.
11. Abdela OA, Bhagavathula AS, Getachew H, Kelifa Y. Risk factors for developing drug-related problems in patients with cardiovascular diseases attending Gondar University Hospital, Ethiopia. $J$ Pharm Bioallied Sci. 2016;8:289-295.

12. Niquille A, Bugnon O. Relationship between drug-related problems and health outcomes: a cross-sectional study among cardiovascular patients. Pharm World Sci. 2010;32(4):512-519. doi:10.1007/s11096010-9401-1

13. Hsu WT, Shen LJ, Lee CM. Drug-related problems vary with medication category and treatment duration in Taiwanese heart failure outpatients receiving case management. J Formos Med Assoc. 2016;115(5):335-342. doi:10.1016/j.jfma.2015.11.014

14. Tegegne GT, Gelaw BK, Defersha AD, Yimam B, Yesuf E. Drug therapy problem among patients with cardiovascular diseases in Felege Hiwot referral hospital, Northeast, Bahir Dar Ethiopia. IAJPR. 2014;4:2828-2838.

15. Gastelurrutia P, Benrimoj SI, Espejo J, et al. Negative clinical outcomes associated with drug-related problems in heart failure (HF) outpatients: impact of a pharmacist in a multidisciplinary HF clinic. $J$ Card Fail. 2011;17(3):217-223. doi:10.1016/j.cardfail.2010.10.009

16. Baena MI, Faus MJ, Fajardo PC, et al. medicine-related problems resulting in emergency department visits. Eur J Clin Pharmacol. 2006;62(5):387-393. doi:10.1007/s00228-006-0116-0

17. Patel P, Zed PJ. Drug-related visits to the emergency department: how big is the problem? Pharmacotherapy. 2002;22(7):915-923. doi:10.1592/phco.22.11.915.33630

18. Howard R, Avery A, Howard P, Partridge M. Investigation into the reasons for preventable drug-related admissions to a medical admissions unit: an observational study. BMJ Qual Saf. 2003;12(4):280285. doi:10.1136/qhc.12.4.280

19. Basger BJ, Moles RJ, Chen TF. Development of an aggregated system for classifying causes of drug-related problems. Ann Pharmacother. 2015;49(4):405-418. doi:10.1177/1060028014568008

20. Al-Dhawailie AA. Inpatient prescribing errors and pharmacist intervention at a teaching hospital in Saudi Arabia. Saudi Pharm J. 2011;19:193-196.

21. Barber N, Rawlins M, Dean Franklin B. Reducing prescribing error: competence, control, and culture. Qual Saf Health Care. 2003;12 (90001):i29. doi:10.1136/qhc.12.suppl_1.i29

22. Poudel R, Piryani RM, Shrestha S, Prajapati A, Adhikari B. Prescription errors and pharmacist intervention at the outpatient pharmacy of Chitwan Medical College. J Chitwan Med Coll. 2015;5(2):20 p. doi:10.3126/jcmc.v5i2.13150

23. Diaz Gomez E, Lazaro Lopez A, Horta Hernandez A. [Analysis of pharmaceutical intervention in outpatients pharmacy department]. Farm Hosp. 2013;37:295-299.

24. Lada P, Delgado G Jr. Documentation of pharmacists' interventions in an emergency department and associated cost avoidance. $\mathrm{Am} \mathrm{J}$ Health Syst Pharm. 2007;64(1):63-68. doi:10.2146/ajhp050213

25. Bergkvist Christensen A, Holmbjer L, Midlöv P, et al. The process of identifying, solving and preventing drug related problems in the LIMM-study. Int $J$ Clin Pharm. 2011;33(6):1010-1018. doi:10.1007/s11096-011-9575-1

26. Ramalho de Oliveira D, Brummel AR, Miller DB. Medication therapy management: 10 years of experience in a large integrated health care system. J Manag Care Pharm. 2010;16(3):185-195. doi:10.18553/jmcp.2010.16.3.185

27. Roane TE, McLin KD. Considerations for Establishing MTM Service Practice Model. In. In: Whalen K, Hardin HC, editors. Medication Therapy Management: A Comprehensive Approach. 2nd ed. New York, NY: McGraw-Hill Education; 2018.

28. McGivney MS, Meyer SM, Duncan-Hewitt W, et al. Medication therapy management: its relationship to patient counseling, disease management, and pharmaceutical care. J Am Pharm Assoc. 2007;47 (5):620-628. doi:10.1331/JAPhA.2007.06129 
29. Bluml BM. Definition of medication therapy management: development of profession-wide consensus. J Am Pharm Assoc. 2005;45 (5):566-572. doi:10.1331/1544345055001274

30. Kang JE, Han NY, Oh JM, et al. Pharmacist-involved care for patients with heart failure and acute coronary syndrome: a systematic review with qualitative and quantitative meta-analysis. J Clin Pharm Ther. 2016;41(2):145-157. doi:10.1111/jcpt.12367

31. North Shewa Zone. North Shewa Zone (Amhara); 2020.

32. Bhagavathula SA, Birarra KM, Tekle TM. Assessment of drugrelated problems and its associated factors among medical ward patients in University of Gondar Teaching Hospital, Northwest Ethiopia: a prospective cross-sectional study. J Basic Clin Pharm. 2017;8:S016-S021.

33. Gizaw K, Dubale M. Drug-related problems and contributing factors among adult ambulatory patients with cardiovascular diseases at Gebretsadik Shawo General Hospital, Bonga, Southwest Ethiopia. $J$ Nat Sci Res. 2017;7:9-16.

34. Urbina $\mathrm{O}$, Ferrández $\mathrm{O}$, Luque $\mathrm{S}$, et al. Patient risk factors for developing a drug-related problem in a cardiology ward. Ther Clin Risk Manag. 2014;11:9-15. doi:10.2147/TCRM.S71749

35. Niriayo YL, Kumela K, Kassa TD, Angamo MT, Frey R. Drug therapy problems and contributing factors in the management of heart failure patients in Jimma University Specialized Hospital, Southwest Ethiopia. PLoS One. 2018;13(10):e0206120. doi:10.1371/journal.pone.0206120

36. Shareef J, Sandeep B, Shastry C. Assessment of drug-related problems in patients with cardiovascular diseases in a tertiary care teaching hospital. J Pharm Care. 2014;2:70-76.
37. Seid E, Engidawork E, Alebachew M, Mekonnen D, Berha AB. Evaluation of drug therapy problems, medication adherence and treatment satisfaction among heart failure patients on follow-up at a tertiary care hospital in Ethiopia. PLoS One. 2020;15(8):e0237781. doi:10.1371/journal.pone.0237781

38. Dempsey JT, Matta LS, Carter DM, et al. Assessment of drug therapy-related issues in an outpatient heart failure population and the potential impact of pharmacist-driven intervention. J Pharm Pract. 2017;30(3):318-323. doi:10.1177/0897190016641491

39. Alazzam S, AbuRuz S, Alefan Q. Drug-related problems in a sample of outpatients with chronic diseases: a cross-sectional study from Jordan. Ther Clin Risk Manag. 2016;12:233-239. doi:10.2147/ TCRM.S98165

40. Abraham RR. Drug-related problems and reactive pharmacist interventions for inpatients receiving cardiovascular drugs. Int J Basic Med Sci Pharm. 2014;3:2049-4963

41. van der Meer P, Gaggin HK, Dec GW. ACC/AHA versus ESC guidelines on heart failure. J Am Coll Cardiol. 2019;73(21):2756. doi:10.1016/j.jacc.2019.03.478

42. Gelchu T, Abdela J. Drug therapy problems among patients with cardiovascular disease admitted to the medical ward and had a follow-up at the ambulatory clinic of Hiwot Fana Specialized University Hospital: the case of a tertiary hospital in eastern Ethiopia. SAGE Open Med. 2019;7:2050312119860401. doi:10.1177/2050312119860401
Therapeutics and Clinical Risk Management

\section{Publish your work in this journal}

Therapeutics and Clinical Risk Management is an international, peerreviewed journal of clinical therapeutics and risk management, focusing on concise rapid reporting of clinical studies in all therapeutic areas, outcomes, safety, and programs for the effective, safe, and sustained use of medicines. This journal is indexed on PubMed Central, CAS,

\section{Dovepress}

EMBase, Scopus and the Elsevier Bibliographic databases. The manuscript management system is completely online and includes a very quick and fair peer-review system, which is all easy to use. Visit http://www.dovepress.com/testimonials.php to read real quotes from published authors. 